\title{
CAMBRIDGE UNIVERSITY EXPEDITION TO JAMAICA
}

\author{
By Dr. V. J. CHA PMAN, \\ UNIVERSITY OF CAMBRIDGE
}

$\mathrm{T}$

HE Expedition left England in two parts, on June 15 and 22, and was scheduled to return on September 19. Owing to the outbreak of war, the main party left Kingston a few days earlier than was anticipated, but in spite of this change of plan the principal items in the programme were carricd to a successful conclusion. The personnel
The primary object of the expedition was to study the development of the cays and of the shore line, especially in the neighbourhood of Kingston, and also the role of the plants and animals concerned in the process. A visit was first paid tu the Morant cays which lie on a shoal about 60 miles south-east of Kingston (see accompanying map, Fig. 1). When, later on, the cays near Kingston were examined, it became appar. ent that the Morant cays form an independent group the structure of which is quite unlike that of the Kingston cays. The Morant cays, four in number, are simple sand cays composed of Halimed $a$ and shell sand together with coral fragments (Fig. 2). These cays were unique among those investigated in that the beach rock forms promenades comparable to those of the low wooded islands of the Great Barrier Reef. These structures always occur on the windward sides of the cays and are heavily eroded. In some of the depressions crystalline salt and alga appeared to be combining to produce a hard crust similar to that consisted of Dr. V. J. Chapman, the leader, Dr. H. Hamshaw Thomas, who took charge of the forest party, Mr. J. A. Steers, who took charge of the schooner party on her voyage around the island, Mr. J. S. Colman in charge of the zoology, Mr. W. R. Philipson, Mr. J. Iofthouse the surveyor, Mr. K. R. Sporne, and Mr. D. J. Crisp. We were fortunate in being able to co-opt three persons in Jamaica, and it is a pleasure to record how much their inclusion helped the expedition. The local members were Mr. C. E. Hamshere who assisted the geographers, and Miss O. Baxter and Miss L. Scudamore who aided the forest party. The Expedition was largely financed by the Royal Society, and our thanks are due to that body and other institutions which provided money, and also to the Government departments of Jamaica and private residents in the island whose ready co-operation greatly facilitated our work. formed on the surface of the promenade, and it is hoped that an analysis of the crust and the algalsalt mixture may throw some light on its formation. Whilst the height of the promenades on the Queensland islands suggested that a slight fall in sea-level had occurred, we came to the conclusion that this was not the solution on the Morant cays, but that storm waves and spray would probably account for their height.

Of the cays in Portland Bight, all but two are built up largely of Halimeda sand, whilst those off Port Royal (outside Kingston Harbour) form a graded series extending from the outer cays, with coarse coral on the exposed south-east and south sides, to the inner sandy cays, with only a few boulders on their weather sides. The similarity of the environment of these two groups of cays makes it very difficult to explain why one set is so different from the other. Many of the cays 


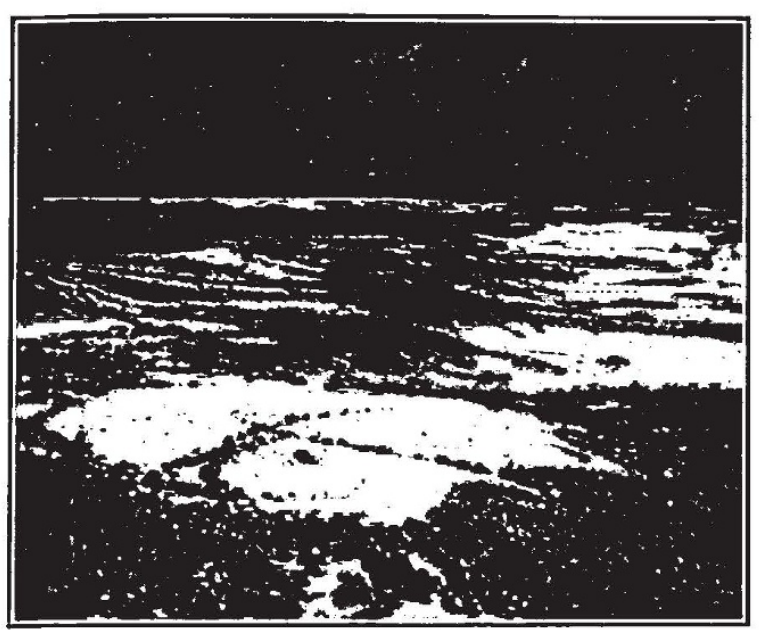

Fig. 2.

IPOMGA AND LOW SAND.DUNES, SOUTH EAST Cay, Moraxt Cays.

possess one or more lines of beach rock lying at varying distances off-shore, and it would seem that these represent former outlines of the cays and they might therefore be used to indicate changes of shape. A study of the physiography of the Palisadoes, together with what is known of its past history, suggests very strongly that this sand and shingle spit rests on a rocky ledge, and that it has united several former shoals or cays which are now represented by the stable salients Plumb Point, Little Plumb Point, and Rocky Point. There are three factors which have controlled the development of this spit in the past and which will determine any future change.

(1) Hurricanes. These are capable of opening up breaches in the spit and re-isolating the individual cays.

(2) Earthquakes. These may have the same effect.

(3) Sand and shingle movement from east to west due mainly to wave action. Normally the evolutionary work of this last factor predominates, but it has been upset time and again in the past by the single or combined effect of the first two.

In other parts of the world where coral reefs are to be found, the calcareous red algæ play no incon. siderable part in their formation, and hence it was surprising to note how insignificant this group of algæ are in Jamaican waters. It may be said that the cays and reefs of Jamaica are conspicuous by the comparative paucity of living coral and calcareous red algæ, although conditions would appear to be favourable for both. Halimeda, in giving rise to a sand, is the only alga which plays any real part in shore-line development, but even this genus is not as abundant as might be expected and it seems that its maximum abundance must have been reached in the past. The observation that many of the cays do not appear to occupy greater areas than they have in the past, as revealed by lines of former beach rock, strongly supports the thesis that fresh supplies of Halimeda sand are not being produced at a great rate.

The mangroves, of which there are three principal species, Rhizophora mangle, Avicennia nitida and Laguncularia racemosa, form the principal vegetation which is concerned with shore line development in this part of the world. They are completely absent from the Morant cays, and this can probably be explained by the fact that the dominant winds blow from the south-east and so any seeds would have to travel over a considerable distance in order to reach the cays. With a persistent wind in this quarter, colonization from Jamaica is out of the question even though it is so near. By way of contrast, the cays in Portland Bight and off Port Royal bear all three species. The mangrove vegetation can be divided into three groups : $(a)$ reef mangroves with roots in the holes and crevices of the boulders; $(b)$ mud mangroves occurring at the mouths of estuaries; and $(c)$ sand mangroves growing on the sand cays and sand spits. Those in group $(a)$ play no part in the

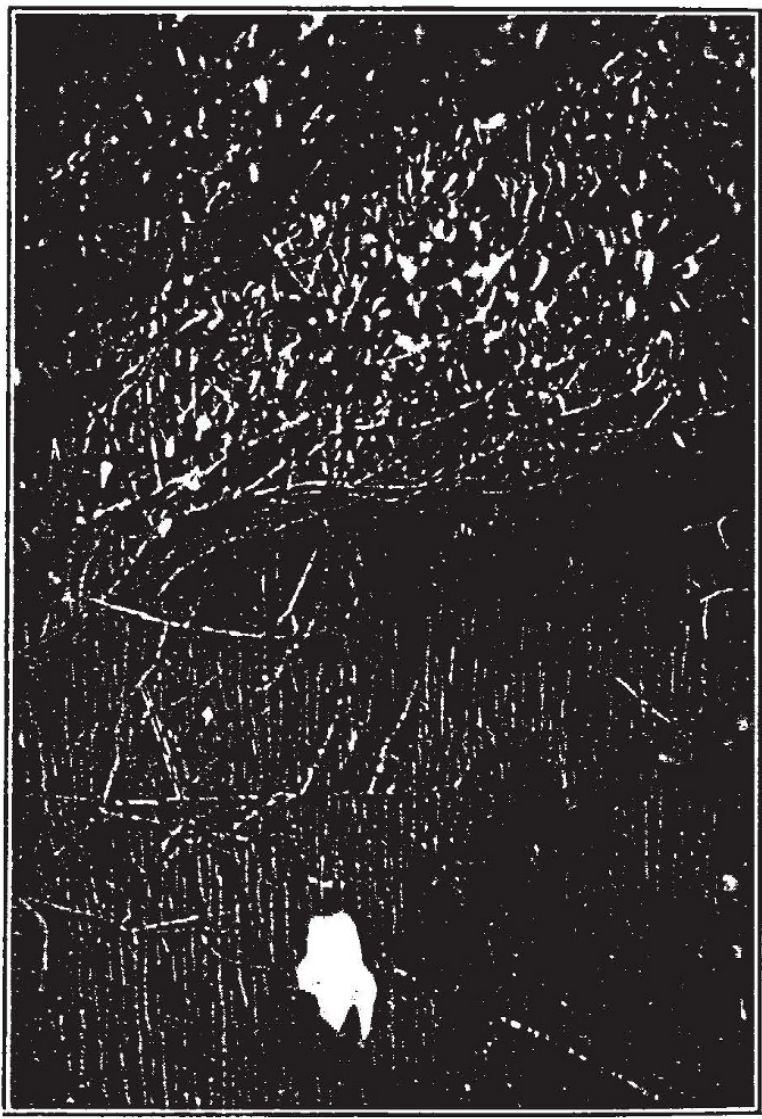

Fig. 3.

Pneumatophores of Avicennia nitida. 
formation of new land, but those in group (c) may spread and unite several small sand cays or ridges and so produce one large swamp. This has undoubtedly occurred along the inner edge of the Palisadoes and is taking place to-day in the Bogue islands near Montego Bay.

As the tidal range in Jamaica is very small, any zonation of the different mangroves is not easy to distinguish. In protected bays, on the leeward side of cays, and along rivers, Rhizophora forms a narrow outer fringe with Avicennia behind, whilst Laguncularia tends to mix in with the Avicennia when the ground becomes slightly higher and drier. In exposed sand-spit areas, however, Laguncularia forms the outer fringe with Avicennia behind, whilst Rhizophora is confined to the damper pools and depressions. Ultimately the mangrove vegetation yields to dune, salina, or freshwater swamp, depending on the local conditions. The most active production of new land by mangroves is taking place at the mouths of rivers, but even in some of these localities exposure to wave action has occasionally brought about an onset of crosion. In such places old mangroves lie uprooted in front of the protecting ridge, whilst seedlings never have an opportunity to establish themselves. In other places where there is very little mud or sand deposition the mangroves produce a marine peat, but it is evident that the formation of new land by this method must take an extremely long time; in the end it results in a much more solid substrate than is normally associated with mangroves.

Particular attention was paid to the ecology of Avicennia nitida and the functions of its pneumatophores (Fig. 3). The tides around Jamaica permit of one major (nine inches to one foot) and one minor (three to five inches) tide a day, and observations showed that only the major tide covered the soil in much of the swamps. In addition to this diurnal fluctuation there were the spring tidal cycles, and it was evident that in some of the swamps quite a number of days could elapse between two floodings. It was also estab. lished that Avicennia grew on three distinct types of soil : (a) sandy soil ; (b) muddy soil ; (c) peat. The oxygen content of the soil water was very low, ranging from 0 to 0.26 per cent, and although bubbles of gas could be obtained from most positions within a swamp, upon analysis such gas always yielded a low oxygen value, the average being about 7 to 8 per cent. This is very different from the concentration in the atmosphere, and it is probably insufficient for the respiratory meta. bolism of the lateral roots. Analyses of the gas contained in the pneumatophores and lateral roots showed that it was not very different from that of the atmosphere so far as the oxygen and carbon dioxide content were concerned. This means that the pneumatophores must form a channel for gaseous interchange. Whenever parts of the pneumatophores were below the soil surface they bore slender horizontal rootlets at a depth of about $1 \mathrm{~cm}$. If, however, the whole of the pneumatophore was exposed, as, for example, when the lateral roots crept among the boulders or were exposed upon the beach, the horizontal rootlets would be absent or else growing out directly from the lateral roots. These are evidently the absorbing organs, and normally they develop from the pneumatophores. Some evidence was also obtained to show that, whilst not primarily organs of respiration, nevertheless the pneumatophores do exhibit some respiratory activity.

The zoologists, Mr. Colman and Mr. Crisp, spent most of their time collecting for the British Museum, one of the more interesting finds being Liltorina minima, of which only three specimens have previously been known. Three level-traverses were made across well-vegetated beach-rock and from one of these, which exhibited excellent algal zonation, samples of the flora were also taken. A tide gauge was established at Port Royal and from the records obtained it is hoped to secure some data about the relative positions of the different animals and plants in relation to tide-levels. T. A. Stephenson and his school have shown that on the South African coast, where the tidal range is comparable to that at Plymouth, systematically related animals tend to occupy the same ecological positions as at Plymouth. It therefore seemed worth while to compare with these two places the corresponding distribution in the Caribbean where the range of tide is very small. It soon became evident that there is, on the whole, a remarkable paucity of living coral around the cays, especially the Morant cays, and this is striking because in similar places off the Queensland coast masses of coral would be encountered. At present there seems to be no adequate explanation of this feature, but it is clear that the cays and reefs are not coral in any full sense of the term. The general conclusion is that the Jamaican marine fauna, though varied, is, nevertheless, somewhat scanty.

Very little can be recorded about the activitics of the forest party because the collections, which have been left in Jamaica for safety, have yet to be examined. Dr. Thomas collected much material of the monotypic genus Rhipidopteris peltata and also of the genus Elaphoglossum, both of which are imperfectly known. Messrs. Philipson and Sporne, apart from collecting for their own purposes, secured a collection of wood specimens for the Imperial Bureau of Forestry at Oxford. 